\title{
Pengujian Black Box pada Aplikasi Perpustakaan Menggunakan Teknik Equivalence Partitions
}

\author{
Bayu Aji Priyaungga ${ }^{1}$, Dwi Bayu Aji ${ }^{2}$, Mukron Syahroni ${ }^{3}$, Nurul Tri Sukma Aji ${ }^{4}$, Aries Saifudin ${ }^{5}$ \\ Teknik Informatika, Universitas Pamulang, Jl. Raya Puspitek No.46, Buaran, Serpong, Tangerang \\ Selatan, Banten, Indonesia, 15310 \\ e-mail: ${ }^{1}$ Bayuuups98@gmail.com, ${ }^{2}$ dwiangin@gmail.com, ${ }^{3}$ msyahroni@gmail.com, \\ ${ }^{4}$ Nurultrisukmaaji@gmail.com, ${ }^{5}$ aries.saifudin@unpam.ac.id
}

Submitted Date: June $12^{\text {th }}, 2020$

Revised Date: August 01 ${ }^{\text {st }}, 2020$
Reviewed Date: July $17^{\text {th }}, 2020$

Accepted Date: August 02 $2^{\text {nd }}, 2020$

\begin{abstract}
The library application is used to help manage and document transaction activities in the library which include borrowing and repaying. Library applications must be free of errors, because if they contain errors can cause harm to providers, managers, or members of the library. To provide a guarantee that the library application is free from errors, testing needs to be done. Software testing is an activity aimed at finding and finding errors and bugs in an application, which aims to minimize the losses that occur due to system errors. In this study, the proposed library application testing is Black Box. Black Box Testing is a test based on the appearance (interface) and functions of the software itself and not from the source code of the program. Black Box Testing has several methods, one of which is Equivalence Partitions, the method we use for testing the software. Equivalence Partitions are methods that discuss valid or not entered into the software, and observe the accuracy of the input. So that the side of the error is known. The test results have proven that the library application that has been developed is error free and meets all the requirements set.
\end{abstract}

Keywords: Black Box Testing; Equivalence Partitions; Library Applications

\begin{abstract}
Abstrak
Aplikasi perpustakaan digunakan untuk membantu mengelola dan mendokumentasikan aktifitas transaksi di perpustakaan yang mencakup peminjaman dan pengembalian. Aplikasi perpustakaan harus bebas dari kesalahan, karena jika mengandung kesalahan dapat menyebabkan kerugian bagi penyedia, pengelola, atau anggota perpustakaan. Untuk memberikan jaminan bahwa aplikasi perpustakaan telah bebas dari kesalahan, maka perlu dilakukan pengujian. Pengujian perangkat lunak merupakan kegiatan bertujuan untuk mencari dan menemukan kesalahan dan bugs pada sebuah aplikasi, yang bertujuan untuk meminimalisir kerugian yang terjadi akibat kesalahan sistem. Pada penelitian ini diusulkan pengujian aplikasi perpustakaan secara Black Box. Pengujian secara Black Box merupakan pengujian berdasarkan dari tampilan (interface) dan fungsi-fungsi dari perangkat lunak itu sendiri serta bukan dari source code program tersebut. Pengujian Black Box memiliki beberapa metode salah satunya Equivalence Partitions, metode yang kami gunakan untuk pengujian perangkat lunak tersebut. Equivalence Partitions adalah metode yang membahas tentang valid atau tidak masukkan yang dimasukkan pada perangkat lunak, serta mengamati akurasi dari masukan tersebut. Sehingga diketahui sisi kesalahannya. Hasil pengujian telah membuktikan bahwa aplikasi perpustakaan yang telah dikembangkan bebas dari kesalahan dan sudah memenuhi semua persyaratan (requirement) yang ditetapkan.
\end{abstract}

Kata kunci: Black Box Testing; Equivalence Partitions; Aplikasi Perpustakaan

\section{Pendahuluan}

Pengujian terhadap perangkat lunak sangat penting dilakukan dengan tujuan untuk memberikan jaminan kualitas perangkat lunak yang dihasilkan agar bebas dari terjadinya kesalahan (Debiyanti, Sutrisna, Budrio, Kamal, \& 
Yulianti, 2020). Pengujian perangkat lunak adalah suatu proses resmi yang sudah ditetapkan oleh kelompok penguji yang mencangkup item perangkat lunak, beberapa item perangkat lunak yang terhubung atau semua paket perungkat lunak yang diperiksa secara menyeluruh dengan mengoperasikan program di komputer (Utomo, Kurniawan, \& Astuti, 2018). Pengujian perangkat lunak adalah prosedur mengoperasikan sebuah program dengan tujuan menemukan penyimpangan-penyimpangan error pada program tersebut. Prosedur untuk mengoperasikan program komputer serta membandingkan perilaku yang sebenarnya dengan yang diharapkan sehinga bisa menghasilkan produk yang bermutu tinggi.

Telah banyak alat bantu yang dikomputerisasi dalam kehidupan sehari-hari. Komputer telah mendominasi di berbagai bidang kerja atau aktifitas untuk meningkatkan kemudahan, efektifas dan efesiensi sehingga memiliki peranan yang sangat penting (Taufiq, Magfiroh, Yusup, \& Yulianti, 2020). Aplikasi perpustakaan merupakan salah satu contoh penerapan komputerisasi di sekolah untuk efisiensi dan mempercepat pengelolaan data (Salsabilah \& Yulianti, 2019).

Software yang akan diuji adalah sebuah aplikasi perpustakaan. Aplikasi yang dapat digunakan untuk membantu petugas perpustakaan dalam mengatur peminjaman buku data buka dan menyimpan catatannya. Jika terjadi masalah pada software/program atau program error maka akan terjadi kerugian. Bagi petugas perpustakaan, jika aplikasi ini terjadi program error maka akan mengakibatkan hilangnya catatan peminjaman dan berdampak pada jumlah buku yang ada.

Metode yang kami gunakan untuk melakukan pengujian pada aplikasi perpustakaan adalah metode pengujian Black Box. Pengujian fungsional atau pengujian Black Box adalah startegi pengujian yang pengujiannya diturunkan dari rincian program atau item. Sistem adalah 'kotak hitam' yang perilakunya semata-mata bisa ditetapkan dengan menganalisa masukan dan keluaran yang berhubungan. Cara ini disebut dengan pengujian fungsional karena penguji tidak menerapkan perangkat lunak tapi hanya berkepentingan dengan fungsionalitasnya (MZ, 2016).

Rencana penelitian/pengujian pada aplikasi perpustakaan akan menggunakan metode pengujian Black Box dengan teknik Equivalence Partitions.

\section{Metodologi}

Pengujian terhadap perangkat lunak sangat penting dilakukan dengan tujuan untuk memberikan jaminan kualitas perangkat lunak yang dihasilkan agar bebas dari terjadinya kesalahan (Debiyanti, Sutrisna, Budrio, Kamal, \& Yulianti, 2020). Dalam pengujian ini, teknik pengujian Black Box yang kami gunakan untuk melakukan pengujian Aplikasi Perpustakaan.

Ada beberapa macam pengujian perangkat lunak yaitu White Box dan Black Box. Pengujian White Box dan Black Box memiliki tujuan dan cara yang berbeda, sehingga keduanya saling melengkapi.

\subsection{Pengujian White Box}

Pengujian White Box ialah pengujian yang berfokus terhadap prosedur serta logika kode dari aplikasi yang dibuat. Pada pengujian White Box, penguji bertugas untuk menganalisa dan menemukan error pada kode program (Siagian, 2018).

Pengujian White Box mencakup analisa jalur dasar dengan membuat flow graph dari kode program dan menentukan nilai kompleksitas siklomatik untuk menentukan jumlah pengujian (Pratala, Asyer, Prayudi, \& Saifudin, 2020). Kemudian dilanjutkan dengan membuat uji kasus (test case), membuat source code untuk test unit, dan mengeksekusi test unit yang telah dibuat, serta mengevaluasi hasilnya.

Pengujian White Box dilakukan mengikuti tahapan berikut ini:

a. Menganalisa kode program untuk mengidentifikasi jalur eksekusi dengan membuat flow graph, menghitung kompleksitas siklomatik, dan mengidentifikasi jalur.

b. Membuat test case untuk pencarian error pada kode program yang dibuat oleh orang yang mengerti program atau biasa disebut programmer.

c. Membuat kode program pengujian unit (unit test)

\subsection{Pengujian Black Box}

Pengujian Black Box adalah pengujian yang memverifikasi hasil eksekusi aplikasi berdasarkan masukan yang diberikan (data uji) untuk memastikan fungsional dari aplikasi sudah sesuai dengan persyaratan (requirement) (Febrian, Ramadhan, Faisal, \& Saifudin, 2020). Pengujian Black Box ialah pengujian yang berfokus pada interface atau tampilan dan pengujian fungsional 
yang terdapat pada aplikasi, serta kesesuaian pada alur fungsi yang dibutuhkan oleh user. Pengujian Black Box tidak menguji berdasarkan source code program (Siagian, 2018).

Pengujian Black Box dilakukan mengikuti tahapan berikut ini:

a. Membuat test case untuk pengujian fungsifungsi yang terdapat di aplikasi

b. Membuat test case untuk pengujian kesesuaian flow atau alur dari kerja suatu fungsi pada program cocok dengan apa yang dibutuhkan dan permintaan dari pengguna

c. Mencari bugs/error berdasarkan tampilan (interface) pada aplikasi

Dalam melakukan pengujian harus memilih teknik yang tepat, yaitu teknik yang dapat menemukan kesalahan yang belum terdeteksi sehingga dapat meningkatkan kualitas software (Hendri, Manurung, Ferian, Hanaatmoko, \& Yulianti, 2020). Pada penelitian ini digunakan metode Equivalence Partitions untuk melakukan pengujian. Equivalence Partitions merupakan pengujian yang didasarkan pada masukan data di setiap form (Maturidi, 2014). Metode pengujian Equivalence Partitions membagi domain masukan dari program ke dalam masing-masing kelas data. Equivalence Partitioning merupakan sebuah pengujian berdasarkan masukkan data pada setiap form yang memecah domain masukan ke dalam kelompok valid dan tidak valid (Aziz, Setiawan, Khanh, Nurdiyansyah, \& Yulianti, 2020).

Pengujian ini menggunakan beberapa tahapan, tahapan yang pertama dimulai dengan membuat uji kasus (test case) dari perangkat lunak yang akan diuji. Selanjutnya mengeksekusi setiap uji kasus yang dibuat dan mendokumentasikan pengujian untuk menganalisa keefektifannya (Jaya,
Gumilang, Tresnawati, Andersen, \& Desyani, 2019). Dari pengujian yang dilakukan dapat dilihat pada tabel test case dibuat sebagai acuan berhasil tidaknya pengujian tersebut (Arochman, Darmawan, \& Santoso, 2016).

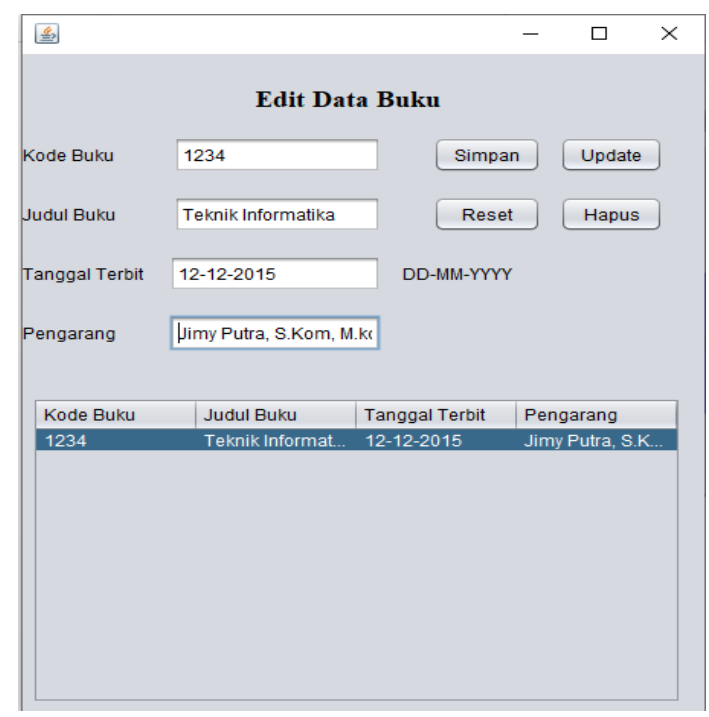

Gambar 1 Form Data Buku

Berdasarkan form pada Gambar 1, terdapat beberapa rencana pengujian, rencana pengujian KODE BUKU, data akan valid jika diisi dengan memasukkan angka (contohnya "123") dan tidak boleh kosong. Sebaliknya data tidak valid jika diisi dengan huruf (contohnya "abc"). Kolom JUDUL BUKU diisi dengan memasukkan judul buku dan harus memasukkan huruf dan tidak boleh kosong. Kolom TANGGAL TERBIT akan valid jika diisi dengan format tanggal dd-mm-yyyy dan tidak boleh kosong. Kolom NAMA PENGARANG diisi dengan nama pengarang dengan memasukkan huruf dan tidak boleh kosong.

Tabel 1 Rancangan Test Case Form Data Buku

\begin{tabular}{|c|l|l|}
\hline ID & \multicolumn{1}{|c|}{ Deskripsi Pengujian } & Hasil yang Diharapkan \\
\hline A01 & $\begin{array}{l}\text { Mengisi KODE BUKU dengan "1234567890" , mengisi JUDUL } \\
\text { BUKU dengan "30 Hari Mahir Membuat Sotware dengan Java", } \\
\text { mengisi TANGGAL TERBIT dengan "20-01-2020", mengisi } \\
\text { NAMA PENGARANG dengan "Nurul Aji S.Kom, M.Kom" } \\
\text { kemudian klik tombol TAMBAH }\end{array}$ & $\begin{array}{l}\text { Data buku dengan kode } \\
\text { buku 1234567890 akan } \\
\text { tersimpan ke database }\end{array}$ \\
\hline A02 & $\begin{array}{l}\text { Mengisi KODE BUKU dengan "BBB" atau tidak diisi , mengisi } \\
\text { JUDUL BUKU dengan "123123" atau tidak diisi, mengisi } \\
\text { TANGGAL TERBIT dengan "2020-01-20" atau tidak diisi, } \\
\text { mengisi NAMA PENGARANG dengan "123456" atai tidak diisi, } \\
\text { kemudian klik tombol TAMBAH }\end{array}$ & $\begin{array}{l}\text { Data dengan kode buku } \\
\text { BBB gagal disimpan ke } \\
\text { database dan akan tampil } \\
\text { pesan kode buku harus } \\
\text { berupa angka }\end{array}$ \\
\hline
\end{tabular}




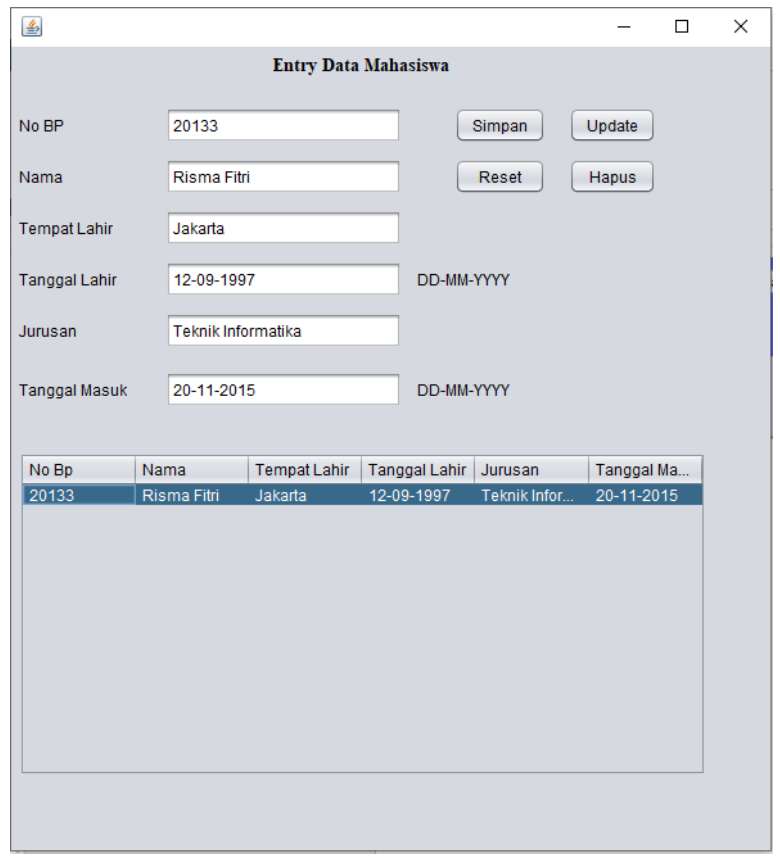

Pada Gambar 2 terdapat beberapa rencana pengujian, kolom NO BP akan valid jika diisi dengan angka (contoh "1234") dan tidak akan valid jika diisi dengan huruf (contoh "bbb") dan tidak boleh kosong. Kolom NAMA akan valid jika diisi dengan huruf dan tidak akan valid jika diisi dengan angka dan tidak boleh kosong. Kolom TEMPAT LAHIR akan valid jika diisi dengan huruf dan tidak valid jika diisi dengan angka dan tidak boleh kosong. Kolom TANGGAL LAHIR akan valid jika diisi dengan format tanggal DD-MM-YYYY dan tidak boleh kosong. Kolom JURUSAN akan valid jika diisi dengan huruf dan tidak akan valid jika diisi dengan angka dan tidak boleh kosong. Kolom TANGGAL MASUK akan valid jika diisi dengan format tanggal DD-MM-YYYY dan tidak boleh kosong.

Gambar 2 Form Data Mahasiswa

Tabel 2 Rancangan Test Case Form Data Mahasiswa

\begin{tabular}{|c|l|l|}
\hline ID & \multicolumn{1}{|c|}{ Deskripsi Pengujian } & \multicolumn{1}{|c|}{ Hasil yang Diharapkan } \\
\hline B01 & $\begin{array}{l}\text { Mengisi NO BP dengan "123456", mengisi NAMA dengan } \\
\text { "Ahmad", mengisi TEMPAT LAHIR dengan "JAKARTA", } \\
\text { mengisi TANGGAL LAHIR dengan "18-10-1990", mengisi } \\
\text { JURUSAN dengan "Teknik Informatika", mengisi TANGGAL } \\
\text { MASUK dengan "12-03-2019" }\end{array}$ & $\begin{array}{l}\text { Data mahasiswa dengan no } \\
\text { BP 123456 akan tersimpan } \\
\text { ke dalam database }\end{array}$ \\
\hline B02 & $\begin{array}{l}\text { Mengisi NO BP dengan "AAAA" atau tidak diisi , mengisi } \\
\text { NAMA dengan "123" atau tidak diisi, mengisi TEMPAT } \\
\text { LAHIR dengan "123" atau tidak diisi, mengisi TANGGAL } \\
\text { LAHIR dengan "18-10-1990" atau tidak diisi, mengisi } \\
\text { JURUSAN dengan "123" atau tidak diisi, mengisi TANGGAL } \\
\text { MASUK dengan "12-03-2019" atau tidak diisi }\end{array}$ & $\begin{array}{l}\text { Data mahasiswa dengan no } \\
\text { BP AAAA gagal disimpan } \\
\text { ke dalam database dan } \\
\text { menampilkan pesan no BP } \\
\text { harus angka }\end{array}$ \\
\hline
\end{tabular}




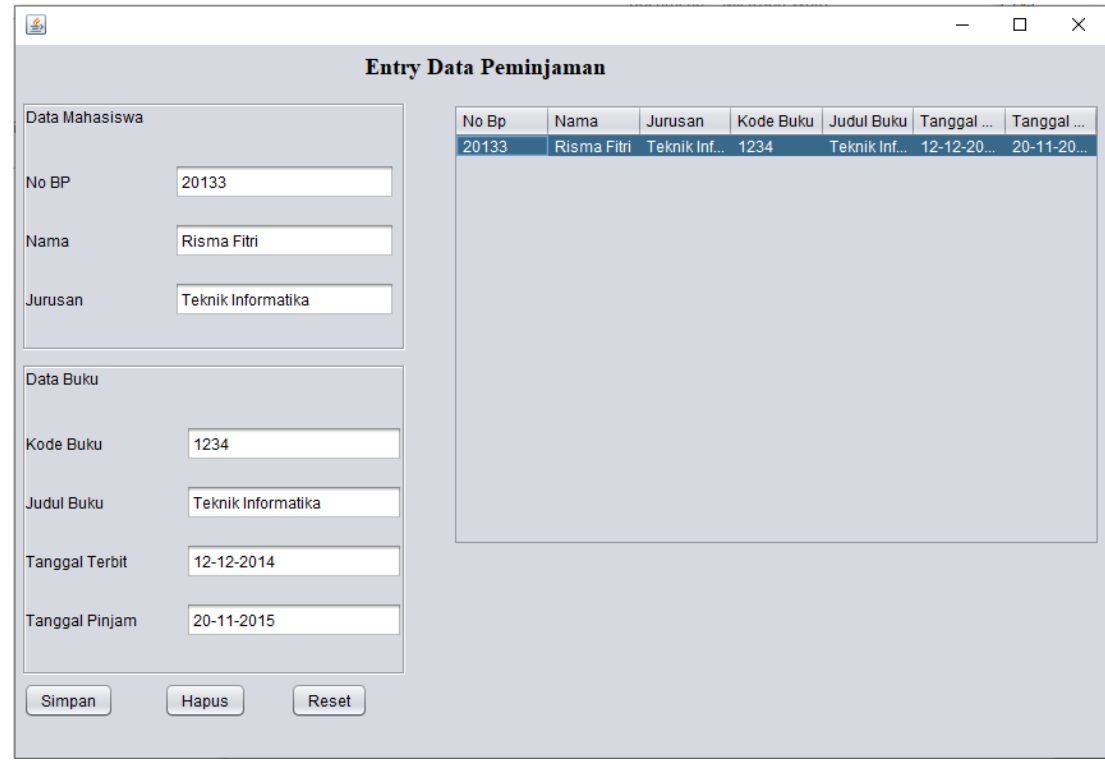

Gambar 3 Form Data Peminjaman

Pada gambar 3 terdapat beberapa rencana pengujian, kolom NO BP akan valid jika diisi dengan angka dan tidak akan valid jika diisi dengan huruf dan tidak boleh kosong. Kolom NAMA akan valid jika diisi dengan huruf dan tidak akan valid jika diisi dengan angka dan tidak boleh kosong. Kolom JURUSAN akan valid jika diisi dengan huruf dan tidak akan valid jika diisi dengan angka dan tidak boleh kosong. Kolom KODE BUKU akan valid jika diisi dengan angka dan tidak akan valid jika diisi dengan huruf dan tidak boleh kosong. Kolom JUDUL BUKU akan valid jika diisi dengan huruf dan tidak akan valid jika diisi dengan angka dan tidak boleh kosong. Kolom TANGGAL TERBIT akan valid jika diisi dengan format tanggal DD-MM-YYYY dan tidak boleh kosong. Kolom TANGGAL PINJAM akan valid jika diisi dengan format tanggal DD-MM-YYYY dan tidak boleh kosong.

Tabel 3 Rancangan Test Case Form Data Peminjaman

\begin{tabular}{|c|c|c|}
\hline ID & Deskripsi Pengujian & Hasil yang Diharapkan \\
\hline $\mathrm{C} 01$ & $\begin{array}{l}\text { Mengisi Data Mahasiswa, mengisi NO BP dengan "123456", mengisi } \\
\text { NAMA dengan "Ahmad", mengisi JURUSAN dengan "Teknik" } \\
\text { Mengisi Data Buku, mengisi KODE BUKU dengan "1234", Mengisi } \\
\text { JUDUL BUKU dengan "AAA", mengisi TANGGAL TERBIT } \\
\text { DENGAN "12-02-2020", mengisi TANGGAL PINJAM dengan "01- } \\
\text { 03-2020" }\end{array}$ & $\begin{array}{l}\text { Data peminjaman } \\
\text { dengan nomor BP } \\
123456 \text { dan kode buku } \\
1234 \text { akan tersimpan ke } \\
\text { database }\end{array}$ \\
\hline $\mathrm{C} 02$ & $\begin{array}{l}\text { Mengisi Data Mahasiswa, mengisi NO BP dengan "AAAA" atau } \\
\text { tidak diisi, mengisi NAMA dengan "123" atau tidak diisi, mengisi } \\
\text { JURUSAN dengan "5555" atau tidak diisi } \\
\text { Mengisi Data Buku, mengisi KODE BUKU dengan "BBB" atau } \\
\text { tidak diisi, Mengisi JUDUL BUKU dengan "777" atau tidak diisi, } \\
\text { mengisi TANGGAL TERBIT DENGAN "2020-02-01" atau tidak } \\
\text { diisi, mengisi TANGGAL PINJAM dengan "2020-03-01" atau tidak } \\
\text { diisi }\end{array}$ & $\begin{array}{l}\text { Data peminjaman } \\
\text { dengan nomor BP AAA } \\
\text { dan kode buku BBB } \\
\text { gagal tersimpan ke } \\
\text { database }\end{array}$ \\
\hline
\end{tabular}

\section{Hasil dan Pembahasan}

Rancangan pengujian sudah dibuat, lalu dilakukan pengujian. Hasil dari pengujian kemudian dicatat di dalam kolom pengujian.
Setelah itu dibuat sebuah kesimpulan yang berdasarkan penilaian antara keluaran yang diharapkan dengan keluaran hasil eksekusi aplikasi. Apabila keluaran yang diharapkan sama 
dengan keluaran yang dihasilkan maka pengujian dianggap berhasil. Hasil pengujian dapat dilihat pada Tabel 4.

Tabel 4 Hasil Pengujian

\begin{tabular}{|c|c|c|c|c|}
\hline ID & Deskripsi Pengujian & $\begin{array}{c}\text { Hasil yang } \\
\text { Diharapkan }\end{array}$ & $\begin{array}{c}\text { Hasil } \\
\text { Pengujian }\end{array}$ & Kesimpulan \\
\hline $\mathrm{A} 01$ & $\begin{array}{l}\text { Mengisi KODE BUKU dengan "1234567890" } \\
\text { mengisi JUDUL BUKU dengan "30 Hari } \\
\text { Mahir Membuat Sotware dengan Java", } \\
\text { mengisi TANGGAL TERBIT dengan "20-01- } \\
\text { 2020" , mengisi NAMA PENGARANG } \\
\text { dengan "Nurul Aji S.Kom, M.Kom" kemudian } \\
\text { klik tombol TAMBAH }\end{array}$ & $\begin{array}{l}\text { Data buku } \\
\text { dengan kode } \\
\text { buku } \\
1234567890 \\
\text { akan tersimpan } \\
\text { ke database }\end{array}$ & $\begin{array}{l}\text { Data buku } \\
\text { dengan kode } \\
\text { buku } \\
1234567890 \\
\text { tersimpan ke } \\
\text { database }\end{array}$ & Sesuai \\
\hline A02 & $\begin{array}{l}\text { Mengisi KODE BUKU dengan "BBB" atau } \\
\text { tidak diisi , mengisi JUDUL BUKU dengan } \\
\text { "123123" atau tidak diisi, mengisi TANGGAL } \\
\text { TERBIT dengan "2020-01-20" atau tidak diisi, } \\
\text { mengisi NAMA PENGARANG dengan } \\
\text { "123456" atai tidak diisi, kemudian klik } \\
\text { tombol TAMBAH }\end{array}$ & $\begin{array}{l}\text { Data dengan } \\
\text { kode buku BBB } \\
\text { gagal disimpan } \\
\text { ke database dan } \\
\text { akan tampil } \\
\text { pesan kode } \\
\text { buku harus } \\
\text { berupa angka }\end{array}$ & $\begin{array}{l}\text { Data buku } \\
\text { dengan kode } \\
\text { buku BBB } \\
\text { gagal } \\
\text { tersimpan ke } \\
\text { database dan } \\
\text { keluar pesan } \\
\text { kode buku } \\
\text { harus berupa } \\
\text { angka }\end{array}$ & Sesuai \\
\hline B01 & $\begin{array}{l}\text { Mengisi NO BP dengan "123456", mengisi } \\
\text { NAMA dengan "Ahmad", mengisi TEMPAT } \\
\text { LAHIR dengan "JAKARTA", mengisi } \\
\text { TANGGAL LAHIR dengan "18-10-1990", } \\
\text { mengisi JURUSAN dengan "Teknik } \\
\text { Informatika", mengisi TANGGAL MASUK } \\
\text { dengan "12-03-2019" }\end{array}$ & $\begin{array}{l}\text { Data mahasiswa } \\
\text { dengan no BP } \\
123456 \text { akan } \\
\text { tersimpan ke } \\
\text { dalam database }\end{array}$ & $\begin{array}{l}\text { Data } \\
\text { mahasiswa } \\
\text { dengan no } \\
\text { BP } 123456 \\
\text { tersimpan ke } \\
\text { database }\end{array}$ & Sesuai \\
\hline B02 & $\begin{array}{l}\text { Mengisi NO BP dengan "AAAA" atau tidak } \\
\text { diisi , mengisi NAMA dengan "123" atau tidak } \\
\text { diisi, mengisi TEMPAT LAHIR dengan "123" } \\
\text { atau tidak diisi, mengisi TANGGAL LAHIR } \\
\text { dengan "18-10-1990" atau tidak diisi, mengisi } \\
\text { JURUSAN dengan "123" atau tidak diisi, } \\
\text { mengisi TANGGAL MASUK dengan "12-03- } \\
\text { 2019" atau tidak diisi }\end{array}$ & $\begin{array}{l}\text { Data mahasiswa } \\
\text { dengan no BP } \\
\text { AAAA gagal } \\
\text { disimpan ke } \\
\text { dalam database } \\
\text { dan } \\
\text { menampilkan } \\
\text { pesan no BP } \\
\text { harus angka }\end{array}$ & $\begin{array}{l}\text { Data } \\
\text { mahasiswa } \\
\text { dengan no } \\
\text { BP AAAA } \\
\text { gagal } \\
\text { tersimpan ke } \\
\text { database dan } \\
\text { keluar pesan } \\
\text { no BP harus } \\
\text { berupa angka } \\
\end{array}$ & Sesuai \\
\hline $\mathrm{C} 01$ & $\begin{array}{l}\text { Mengisi Data Mahasiswa, mengisi NO BP } \\
\text { dengan "123456", mengisi NAMA dengan } \\
\text { "Ahmad", mengisi JURUSAN dengan } \\
\text { "Teknik" } \\
\text { Mengisi Data Buku, mengisi KODE BUKU } \\
\text { dengan "1234", Mengisi JUDUL BUKU } \\
\text { dengan "AAA", mengisi TANGGAL TERBIT } \\
\text { DENGAN "12-02-2020", mengisi TANGGAL } \\
\text { PINJAM dengan "01-03-2020" }\end{array}$ & $\begin{array}{l}\text { Data } \\
\text { peminjaman } \\
\text { dengan nomor } \\
\text { BP } 123456 \text { dan } \\
\text { kode buku } 1234 \\
\text { akan tersimpan } \\
\text { ke database }\end{array}$ & $\begin{array}{l}\text { Data } \\
\text { peminjaman } \\
\text { dengan } \\
\text { nomor BP } \\
123456 \text { dan } \\
\text { kode buku } \\
1234 \\
\text { tersimpan ke } \\
\text { database } \\
\end{array}$ & Sesuai \\
\hline $\mathrm{C} 02$ & $\begin{array}{l}\text { Mengisi Data Mahasiswa, mengisi NO BP } \\
\text { dengan "AAAA" atau tidak diisi, mengisi }\end{array}$ & $\begin{array}{l}\text { Data } \\
\text { peminjaman }\end{array}$ & $\begin{array}{l}\text { Data } \\
\text { peminjaman }\end{array}$ & Sesuai \\
\hline
\end{tabular}


NAMA dengan "123" atau tidak diisi, mengisi JURUSAN dengan "5555" atau tidak diisi Mengisi Data Buku, mengisi KODE BUKU dengan "BBB" atau tidak diisi, Mengisi JUDUL BUKU dengan "777" atau tidak diisi, mengisi TANGGAL TERBIT DENGAN "2020-02-01" atau tidak diisi, mengisi TANGGAL PINJAM dengan "2020-03-01" atau tidak diisi

\begin{tabular}{l|l} 
dengan nomor & dengan \\
BP AAA dan & nomor BP \\
kode buku BBB & AAA dan \\
gagal tersimpan & kode buku \\
ke database & BBB gagal \\
& tersimpan ke \\
& database dan \\
& menampilkan \\
& pesan no BP \\
& dan kode \\
& buku harus \\
& berupa angka
\end{tabular}

Guessing agar kita dapat menemukan kesalahan/error lainnya pada pengembangan aplikasi ini sehingga, kualitas aplikasi yang dihasilkan jauh lebih baik (mengingat sudah berulang kali meminimalisir kesalahan) yang nantinya jika system tersebut sudah bebas dari kesalahan maka sistem akan bekerja secara maksimal sekaligus mengoptimalkan kinerja dari user (pengguna)

\section{Referensi}

Arochman, Darmawan, A. S., \& Santoso, F. H. (2016). Otomatisasi Desain Test Case Pengujian Perangkat Lunak Metode Black-Box Testing Dengan Teknik Equivalence Partitioning Menggunakan Algoritma Genetika. 47-55.

Aziz, I. A., Setiawan, B., Khanh, R., Nurdiyansyah, G., \& Yulianti, Y. (2020). Pengujian Black Box pada Aplikasi Sistem Kasir Berbasis Website Menggunakan Teknik Equivalence Partitions. Jurnal Teknologi Sistem Informasi dan Aplikasi, $\quad 3(2), \quad$ 10.32493/jtsi.v3i2.4693. doi:10.32493/jtsi.v3i2.4693

Debiyanti, D., Sutrisna, S., Budrio, B., Kamal, A. K., \& Yulianti, Y. (2020). Pengujian Black Box pada Perangkat Lunak Sistem Penilaian Mahasiswa Menggunakan Teknik Boundary Value Analysis. Jurnal Informatika Universitas Pamulang, 5(2), 162-166. doi:10.32493/informatika.v5i2.5446

Febrian, V., Ramadhan, M. R., Faisal, M., \& Saifudin, A. (2020). Pengujian pada Aplikasi Penggajian Pegawai dengan menggunakan Metode Blackbox. Jurnal Informatika Universitas Pamulang, 5(1), 61-66. doi:10.32493/informatika.v5i1.4340

Hendri, H., Manurung, J. W., Ferian, R. A., Hanaatmoko, W. F., \& Yulianti, Y. (2020). Pengujian Black Box pada Aplikasi Sistem Informasi Pengelolaan Masjid Menggunakan Teknik Equivalence Partitions. Jurnal Teknologi Sistem Informasi dan Aplikasi, 3(2), 107-113. doi:10.32493/jtsi.v3i2.4694 dapat menggunakan teknik pengujian Black Box seperti Boundary Value Analysis atau Error 
Jaya, M. S., Gumilang, P., Tresnawati, Andersen, Y. P., \& Desyani, T. (2019). Pengujian Black Box pada Aplikasi Sistem Penunjang Keputusan Seleksi Calon Pegawai Negeri Sipil Menggunakan Teknik Equivalence Partitions. $4,131-136$.

Maturidi, A. J. (2014). Metode Penelitian Teknik Informatika. Yogyakarta: deepublish.

MZ, M. K. (2016). Pengujian Perangkat Lunak Metode Black-Box Berbasis Equivalence Partitions Pada Aplikasi Sistem Informasi Sekolah. Jurnal Mikrotik, 2-8.

Pratala, C. T., Asyer, E. M., Prayudi, I., \& Saifudin, A. (2020). Pengujian White Box pada Aplikasi Cash Flow Berbasis Android Menggunakan Teknik Basis Path. Jurnal Informatika Universitas Pamulang, 5(2), 111-119. doi:informatika.v5i2.4713

Salsabilah, Z., \& Yulianti, Y. (2019). Perancangan Aplikasi Perpustakaan Berbasis Web pada SMK Negeri 1 Rangkasbitung. Jurnal Teknologi Sistem Informasi dan Aplikasi, 2(1), 9-14. doi:10.32493/jtsi.v2i1.2401

Siagian, L. J. (2018). Otomatisasi Pengujian Perangkat Lunak: Software Test Automation. Yogyakarta: deepublish.

Taufiq, R., Magfiroh, D. A., Yusup, D., \& Yulianti, Y. (2020). Analisis dan Desain Sistem Informasi Pembayaran Sumbangan Pembinaan Pendidikan (SPP) di SMK Avicena Rajeg. Jurnal Teknologi Sistem Informasi dan Aplikasi, 3(1), 15-21. doi:10.32493/jtsi.v3i1.4308

Utomo, D. W., Kurniawan, D., \& Astuti, Y. P. (2018). Teknik Pengujian Perangkat Lunak Dalam Evaluasi Sistem Layanan Mandiri Pemantauan Haji Pada Kementerian Agama Provinsi Jawa Tengah. Simetris : Jurnal Teknik Mesin, Elektro dan Ilmu Komputer, 9(2), 731-746. doi:10.24176/simet.v9i2 